\title{
Perfusion System Controller Strategies DURING AN ECMO SUPPORT
}

\author{
M.Dhinakaran ${ }^{1}$ and S.Abraham Lincon ${ }^{2}$ \\ ${ }^{1,2}$ Department of Instrumentation Engineering, Annamalai University, \\ Annamalai Nagar, Tamil Nadu, India
}

\begin{abstract}
In this work modelling and control of Perfusion system is presented. The Perfusion system simultaneously controls the partial pressures during Extra Corporeal Membrane Oxygenation (ECMO) support. The main Problem in ECMO system is exchange of Blood Gases in the Artificial Lung (Oxygenator).It is a highly Nonlinear Process comprising time-varying parameters, and varying time delays, it is currently being controlled manually by trained Perfusionist. The new control strategy implemented here has a feedback linearization routine with time-delay compensation for the Partial pressuresof Oxygen and Carbon dioxide. The controllers were tuned robustly and tested in simulations with a detailed artificial Lung (Oxygenator) model in Cardiopulmonary bypass conditions. This Automatic control strategy is proposed to improve the patient's safety by fast control reference tracking and good disturbance rejection under varying conditions.
\end{abstract}

\section{KEYWORDS}

Cardio Pulmonary Bypass (CPB), Blood Gas Analyser (BGA), Extra Corporeal Membrane Oxygenator (ECMO)

\section{INTRODUCTION}

ECMO support has been established as a routine treatment used for the patients whose Heart or Lungs is not working properly and is most often used for Bypass procedures, and Heart transplantations. The ECMO procedure is similar to a Heart-Lung bypass used during open-Heart surgery. Extracorporeal Membrane Oxygenation can take over the function of the child's Heart and / or Lungs for a limited time until the child recovers from the initial cause of the failure [4]. Figure 1 shows a new born having respiratory failure is placed in ECMO setup in ICU. The most frequent use for ECMO has been with new born infants with lack of a fully functioning respiratory system or other birth defect,although it may also be helpful in selected cases of severe heart failure in adults and children. During CPB the functions of the Heart and Lungs are taken over by the ECMO setup there by guaranteeing a bloodless, motionless operating field. In Extra Corporeal Membrane Oxygenator the blood is circulated from the venous to the arterial side of the patient's vascular system by a pump in the machine. Additionally an Oxygenator takes over the function of the Lungs by the addition of fresh Oxygen $\left(\mathrm{O}_{2}\right)$ to and the removal of Carbon dioxide $\left(\mathrm{CO}_{2}\right)$ from blood. This Gas exchange is achieved by a gas flow that is in close contact to the Blood pumped through the Oxygenator. This Gas mixture and its partial gas pressures initiate a diffusion process in the Oxygenator, which in turn determines the amount of Oxygen and Carbon dioxide on the arterial side of the patient. The Gas flow and the mixture of Gas that flows 
through the Oxygenator are currently still being manually adjusted to have correct partial gas pressures in the arterial blood [5].

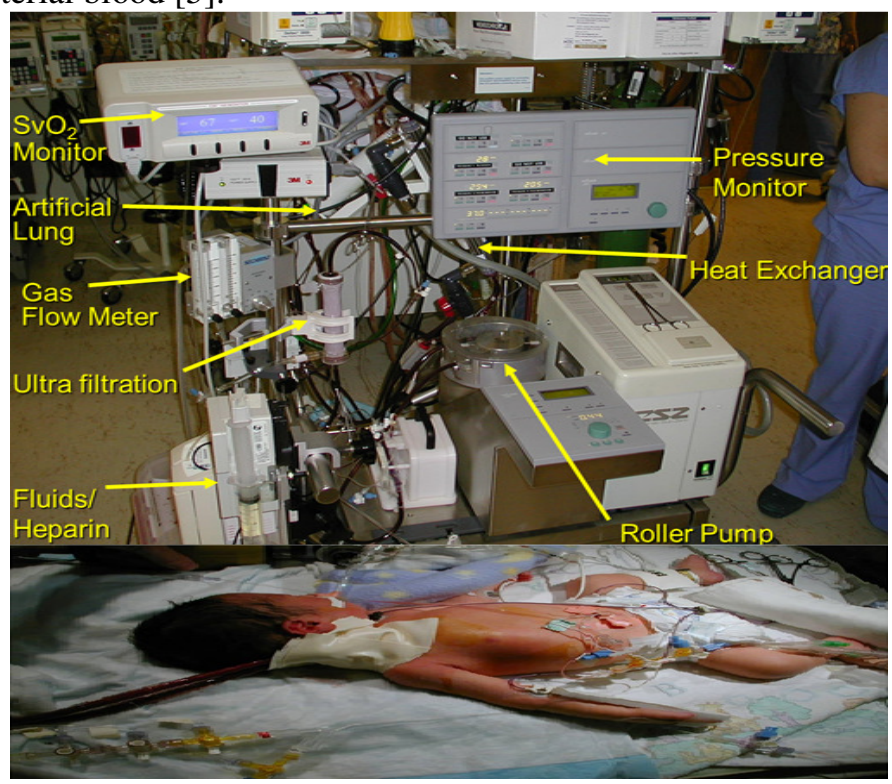

Figure 1. ECMO Setup

This manual control Process can lead to errors, which may cause tissue or nervous cell damage. An automatic blood gas control strategy is suggested to improve the patient's safety by fast control reference tracking of reasonable set points and a good disturbance rejection, which means keeping the blood gas values in physiological ranges during disturbances. In addition to that, the automatic control is suggested to remove workload from the perfusionist staff, and may thereby help to increase the amount of correct decisions in situations of extreme workload.Figure 2 shows the circuit diagram of an ECMO setup.

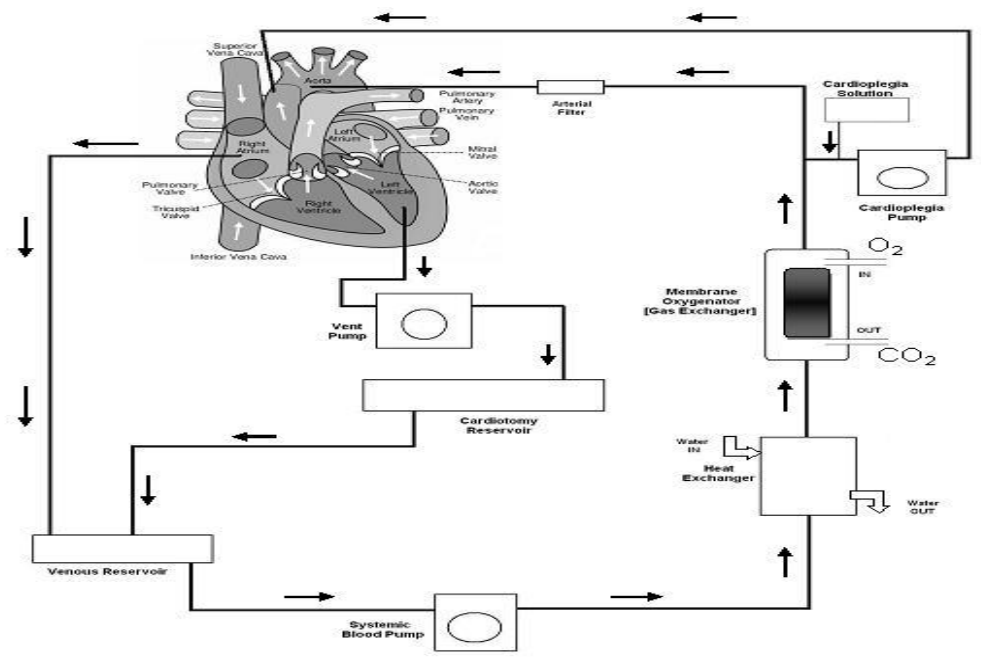

Figure 2.Complete Circuit Diagram of ECMO 


\section{ECMO MODELLING}

As the exchange and transport of oxygen and carbon dioxide are complex biological processes Comprising nonlinearities, time delays, uncertainties, and time-varying parameters, detailed system knowledge is needed for the development of a suitable feedback control [1]. For that reason a model of the blood gas transfer process was developed as follows. The system subject to control was divided into three subsystems: the gas mixer; the Oxygenator, and the Blood Gas analyzer (BGA) as shown in thefigure 3 .

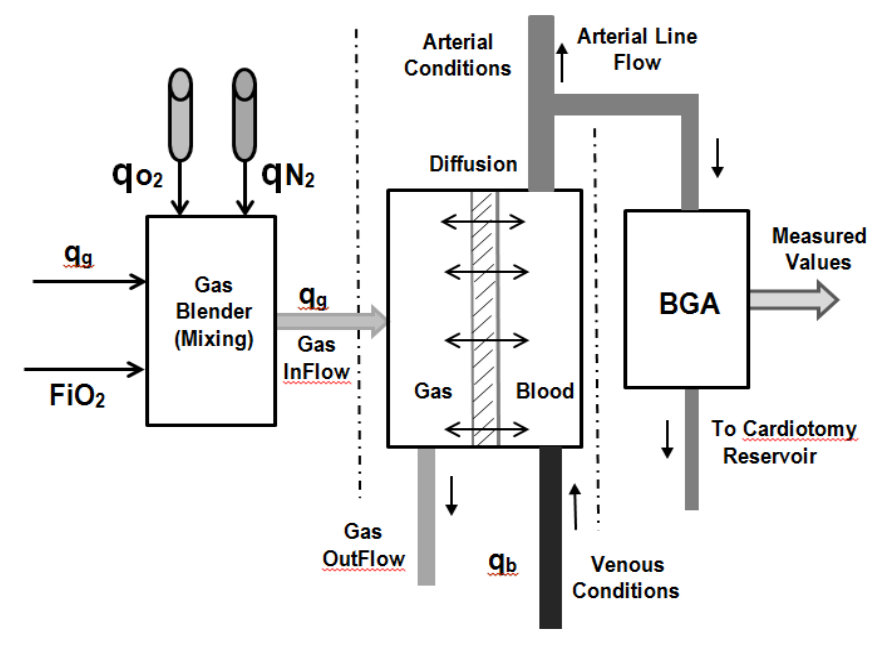

Figure 3. Gas Blender, Oxygenator, and BGA diagram

\subsection{Gas Blender Model Design}

As the gas concentrations are normally set mechanically with flow tubes, an electronic gas mixer was designed based on electronic flow dosage modules.Figure 4 shows the Gas blender, Oxygenator, and Blood gas analyser model diagram. The static output of the gas mixer is given by

$$
\begin{gathered}
\mathrm{Q}_{\mathrm{G}}=\mathrm{QO}_{2}+\mathrm{QN}_{2}+\mathrm{Qco}_{2} \\
\mathrm{QO}_{2}=\mathrm{Q}_{\mathrm{G}} * \mathrm{FiO}_{2} \\
\mathrm{QCO}_{2}=\mathrm{Q}_{\mathrm{G}} * \mathrm{FiCO}_{2} \\
\mathrm{QN}_{2}=\mathrm{Q}_{\mathrm{G}}\left(1-\mathrm{FiO}_{2}-\mathrm{FiCO}_{2}\right)
\end{gathered}
$$

The combination of the two gases is known as inspired Input Oxygen $\left(\mathrm{FiO}_{2}\right) \cdot \mathrm{Q}_{\mathrm{G}}$ is nothing but total gas flow of the cardiopulmonary Blood Gases. $\mathrm{Q}_{\mathrm{G}}$ is measured by blood Gassensor. $\mathrm{Q}_{\mathrm{CO}_{2}}$ is nothing but total flow of carbon dioxide. $\mathrm{Q}_{\mathrm{N}_{2}}$ is nothing but total flow of atmospheric air. $\mathrm{T}_{\mathrm{d} 1}\left(\mathrm{~T}_{\mathrm{g}}\right)$ is a transport delay due to the distance from gas blender to oxygenator and applies to the Oxygen fraction in the gas.The time-delay depends on gas flow and the tubing system. Total time delay for the Gas mixer process based on the equation [1] - [2]. 


$$
T_{d 1}\left(T_{g}\right)=\frac{0.7853}{T_{g}} d_{t, 0 x y}^{2} l_{t, 0 x y}
$$

Where $\mathbf{d}_{\mathbf{t}, \mathbf{o x y}}^{\mathbf{2}}$ is the square diameter of the Gas Blender,and $\mathbf{l}_{\mathbf{t}, \mathbf{o x y}}$ is the length of the Gas Blender to Membrane Oxygenator, $\mathbf{T}_{\mathbf{g}}$ is the Total blood flow in the Membrane Oxygenator.

\subsection{Membrane Oxygenator Model}

The Membrane Oxygenator replicates the functionality of the Human Lungs in that it exposes the blood to regulate amount of $\mathrm{O}_{2}$ and $\mathrm{CO}_{2}$. Gas entering on top inside the fibres while the blood is flowing first down through a Heat Exchanger and then up through the Gas Exchanger. Gas Exchange between Gas and blood phase is a very complicated process involving position dependent quantities and partially nonlinear mechanisms which include Gas transport and diffusion in the Blood or the diffusion across the Membrane. [3]Mass Balance Equation for Gas Stored in the Blood Compartment in membrane Oxygenator.

$$
\mathrm{V} \frac{\mathrm{d}[\mathrm{c}]_{\mathrm{i}}}{\mathrm{dt}}=\mathrm{T}_{\mathrm{b}}\left([\mathrm{C}]_{\mathrm{i}, \text { in }}-[\mathrm{C}]_{\mathrm{i}, \text { out }}\right)+\mathrm{D}_{\mathrm{i}}\left(\mathrm{p}_{\mathrm{i}, \text { ext }}-\mathrm{p}_{\mathrm{i}}\right)+\mathrm{Ri}
$$

Where $\mathrm{V}$ is the Volume of the compartment mixing chamber in an Oxygenator, $[\mathrm{C}]_{\mathbf{i}}$ is the Concentration of the Components, $[\mathbf{D}]_{\mathbf{i}}$ is the Diffusion Capacity over the Membrane Oxygenator, $\left[\mathbf{p}_{\mathbf{i}}\right]$ is the internal and external Partial Pressure of the Membrane Oxygenator, Ri is the external disturbance in membrane Oxygenator cross bonding to chemical reaction. $\mathbf{T}_{\mathbf{b}}$ is the Total Blood flow through in the Membrane Oxygenator.

\subsection{Blood Gas Analysis Model Design}

Blood gases are only sampled a few times a day in order to check blood gas status. This clinical blood gas analyser's use up a few millilitre bloods for each sample, so these devices cannot be used for continuous blood monitoring on a frequent basis (e.g. every second). For our setup we chose the CDI 500 blood gas analyser from Terumo which offers online measurement of $\mathrm{pH}$, $\mathrm{pCO}_{2}, \mathrm{pO}_{2}$, potassium, temperature and etc. The BGA was modelled according to measurements with first order differential equations with its dominant. The modelled BGA time-delay is

$$
\mathrm{T}_{\mathrm{d}_{2}}\left(\mathrm{~T}_{\mathrm{g}}\right)=\frac{0.7853}{\mathrm{~b}_{\mathrm{t} 1}\left(0.01 \mathrm{~T}_{\mathrm{b}}+\mathrm{b}_{\mathrm{t} 0}\right)} \mathrm{d}_{\mathrm{t}, \mathrm{BGA}}^{2} \mathrm{l}_{\mathrm{t}, \mathrm{BGA}}
$$

Where $d_{t, B G A}$ is the diameter of the Blood Gas analyzer tube, $l_{t, B G A}$ is the length of the of the Blood Gas analyzer tube, $\mathbf{b}_{\mathbf{t} \mathbf{0}}$ is the time delay for the Blood Gas Analyzer, $\mathbf{b}_{\mathbf{t} \mathbf{1}}$ is the Conversion factor for Blood Gas Analyser, $\mathbf{T}_{\mathbf{b}}$ is the total blood flow through the Blood Gas Analyser . 


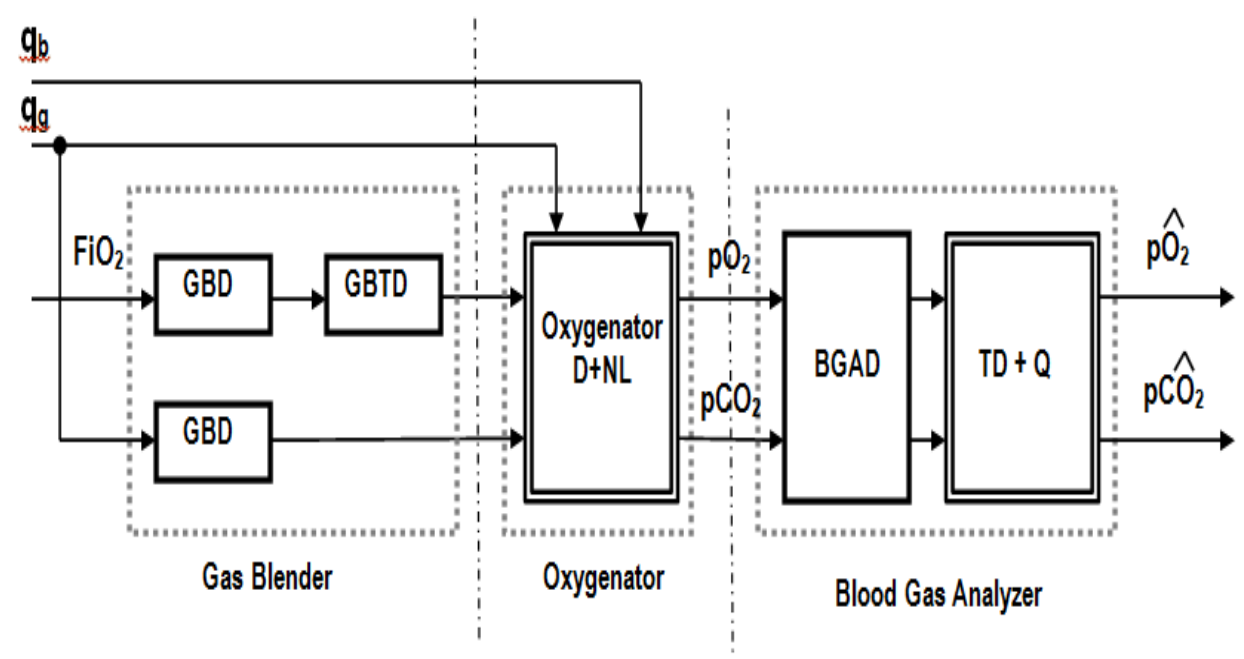

Figure 4. Gas blender, Oxygenator, and Blood Gas Analyser modelDiagram

\subsection{Time Delay}

Total time delay of the blood flow can be calculated by time delay between the Gas blender to Membrane oxygenator $\mathrm{Td}_{1}(\mathrm{Tg})$ and time delay between membrane oxygenator to Blood Gas analysis $\mathrm{T}_{2}(\mathrm{Tg})$.

$$
\mathrm{T}_{\mathrm{d}}\left(\mathrm{T}_{\mathrm{g}}\right)=\mathrm{T}_{\mathrm{d} 1}\left(\mathrm{~T}_{\mathrm{g}}\right)+\mathrm{T}_{\mathrm{d} 2}\left(\mathrm{q}_{\mathrm{g}}\right)
$$

\subsection{Input/OutputLinearization of $\mathrm{O}_{2}$}

The process is linearized with an analytical input/output linearization for the oxygenation process with input $\mathrm{FiO}_{2}$ and output $\mathrm{pO}_{2}$. Direct disturbance to the states can be measured with high dynamics in case of the blood-flow which are measured via the blood-gas analyser the disturbance dynamics are expected to be much slower than the dynamics of the blood gas analyser. So the input oxygen from the Gas blender to membrane Oxygenator as follows.

$$
\mathrm{u}_{\mathrm{oxy}}=\mathrm{fiO}_{2} * \mathrm{p}_{\mathrm{bar}}(10)
$$

The input and output of the oxygen can be linearized with the help of barometric pressure and percentage of inspired input Oxygen depends on the patient respiration.

\subsection{Nonlinear State Space Process Model}

Process model depends on the Gas blender, membrane oxygenator, blood gas analysis and so on. Finally we have to derive the mathematical model for Gas transfer in an oxygenator. So the strong mathematical knowledge should be needed to design the membrane oxygenator model.[3] Initially the model design and control by single input single output (SISO) Processes the may be defined

$$
\begin{aligned}
\dot{X}(t) & =A x(t)+B u(t)(11) \\
Y(t)=C x(t) & +D u(t)
\end{aligned}
$$


Where $\mathrm{x}(\mathrm{t})$ is the state vector; $\mathrm{A}$ is the system matrix;B is the input matrix; $\mathrm{C}$ is the output matrix is zero matrix; $y(t)$ is the output vector ; $u(t)$ is the input control matrix ; [1]

The continuous time invariant state space model for an membrane oxygenator to control the blood gases with the help of controller. The controller approach is based on the mathematical nonlinear model of the gas transfer process in membrane oxygenator. Input control matrix of the single input as followsas

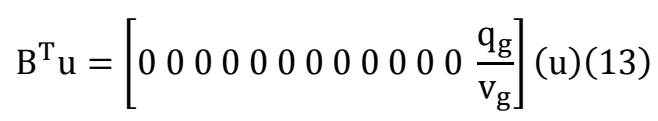

Input vector $\mathrm{u}=\mathrm{pO}_{2}=\mathrm{FiO}_{2} * 760 \mathrm{~mm} \mathrm{Hg}$ for barometric pressures[3]. The state vector may be defined as

$$
X=\left[x_{1} x_{2} x_{3} x_{4} x_{5} x_{6} x_{7} x_{8} x_{9} x_{10} x_{11} x_{12} x_{13}\right]^{T} u
$$

The full process model of the three inputs, two output of the system with input composed of $\mathbf{F i O}_{2}$, Gas flow and Blood flow the output vector is based on pressure of $\mathbf{O}_{2}$ and $\mathbf{C O}_{2}$

$$
\mathrm{Y}^{\mathrm{T}}=\left[\mathrm{pO}_{2} \mathrm{pCO}_{2}\right]^{\mathrm{T}}
$$

\section{CONTROLLERDESIGN}

The $\mathrm{pCO}_{2}$ process is much less critical in control terms; compared with the $\mathrm{pCO}_{2}$ process need not Linearization of the carbon dioxide for $\mathrm{pCO}_{2}$ controller design. $\mathrm{pO}_{2}$ process is more complicated in control terms. An input/output state linearization routine with delay-time compensation and an external linear gain scheduled controller had to be developed to handle the strong static and dynamic nonlinearity and the time delay at input and output. Like the $\mathrm{pO}_{2}$ controller was gain-scheduled in dependence of blood flow through the oxygenator.[1] The PID$\mathrm{pO}_{2}$ and the PID- $\mathrm{pCO}_{2}$ controllers, were discretized at the sampling time of the blood gas analysis, $\mathrm{Ts}, \mathrm{BGA}=6 \mathrm{~s}$.

\subsection{PID Controller}

The Proportional-Integral-Derivative (PID) method is a kind of feedback controller which is generally based on the error (e) between desired set point and measured process value. Three parameters must be designed in the PID Controller and each parameter has an effect on the error. The transfer function of the PID controller is writtenas

$$
C(\mathrm{~S})=\frac{\mathrm{U}(\mathrm{S})}{\mathrm{E}(\mathrm{s})}=\mathrm{k}_{\mathrm{p}}+\frac{\mathrm{K}_{\mathrm{i}}}{\mathrm{S}}+\mathrm{K}_{\mathrm{d}}
$$

\section{DISCUSSI ON}

By using a detailed model of the gas blender, the Oxygenator, and the Blood gas analysis, a feedback control could be developed for the simultaneous control of Oxygen and Carbon dioxide partial pressures. As the control input for $\mathrm{pO}_{2}$, the oxygen fraction in the gas flow $\mathrm{FiO}_{2}$ to the oxygenator was used. As the control input for $\mathrm{pCO}_{2}$, the total gas flow qg to the Oxygenator was 
used. The direct coupling of $\mathrm{q}_{\mathrm{g}}$ to the $\mathrm{FiO}_{2}$ control input is similar to a disturbance at $\mathrm{pCO}_{2}$ controller gas flow input changes and can be seen as a disadvantage. The advantages of this strategy are that an additional $\mathrm{CO}_{2}$ gas supply is saved and that this technique is commonly used in most cardiovascular Heart surgery centres. The $\mathrm{pO}_{2}$ process is more complicated in control terms. An input/output state linearization routine with delay-time compensation and an external linear gain scheduled controller had to be developed to handle the strong static and dynamic nonlinearity and the time delay at input and output. In contrast to that, a PI controller was developed for the $\mathrm{O}_{2}$ process, as it shows an output delay time only and much less static and dynamic nonlinearities. The controllers were tested in simulations over the whole operating range with the model and incorporated uncertainty and showed a good performance and robust stability

\section{SIMULATION RESULTS}

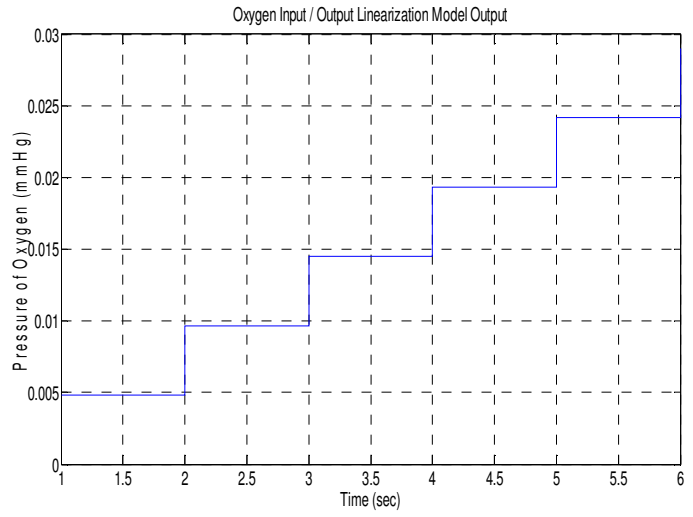

Figure 5. A. Oxygen linearisation I/O Response

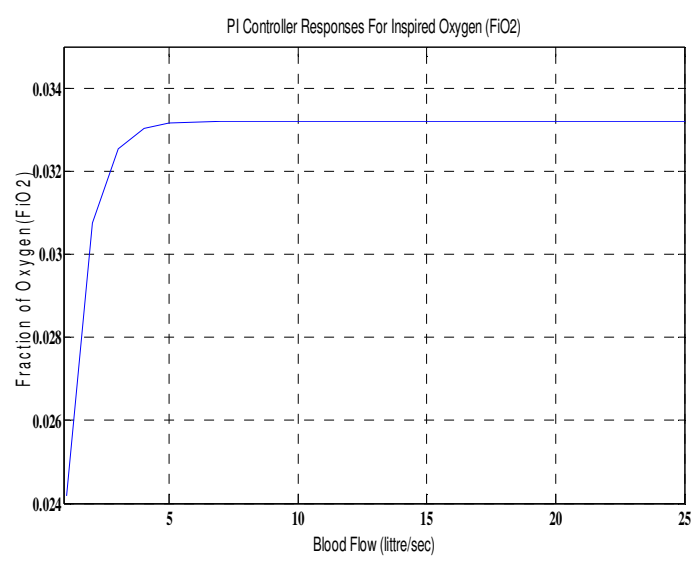

Figure 6. Fraction of Oxygen (FiO2) Control Response 
International Journal on Soft Computing (IJSC) Vol. 5, No. 3, November 2014

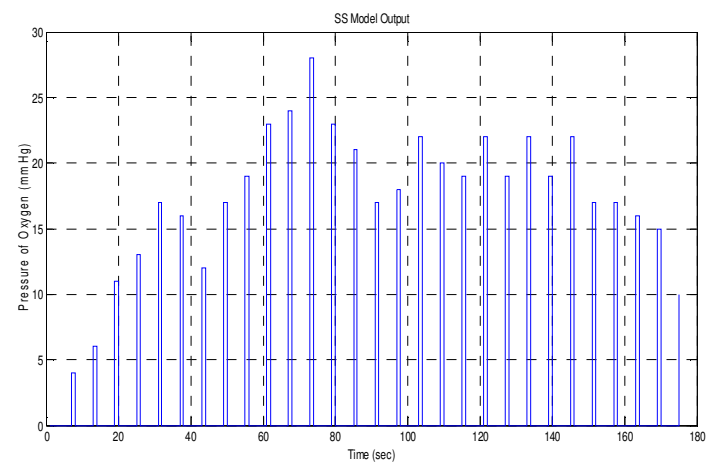

Figure 7. State Space output for pressure of oxygen

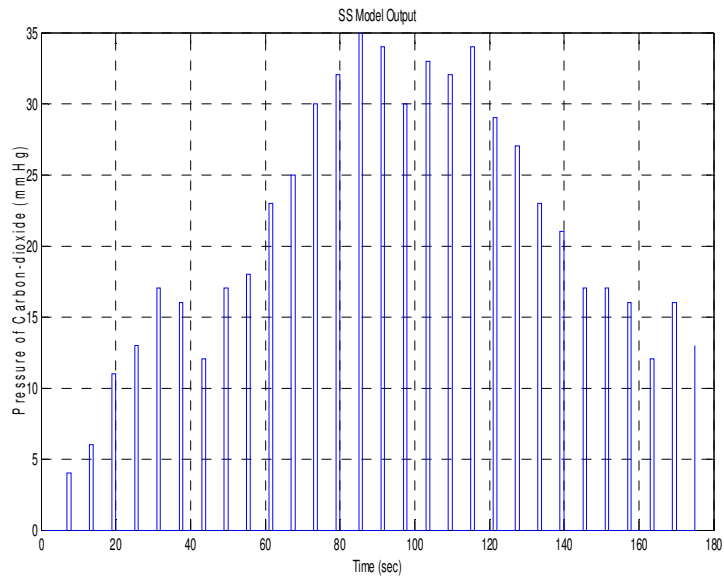

Figure 8. State Space output for pressure of carbon dioxide

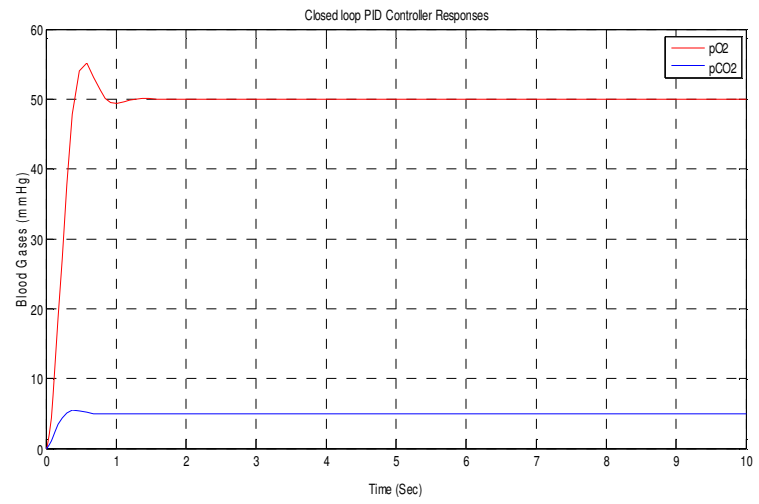

Figure 9. PID Controller Responses

\section{CONCLUSION}

The proposed model of the blood-gas controller for Oxygen and Carbon dioxide exchange during ECMO support shows fast reference tracking and good disturbance rejection results, while process coupling is kept low. This is possible because of the Oxygen process I/O linearisation and time-delay compensation. Linear process models for the two-input- two output plant were 
obtained for the linearised system without time-delay over the complete operating range during surgeries. Uncertainties in the resulting transfer functions, as well as time delay uncertainties were modeled in a multiplicative output uncertainty bound. Only one linear controller was applied in nonlinear simulation with a validated Oxygenator model and showed very good results However, lumping uncertainties of various sources at the system output in a multiplicative uncertainty bound is suggested to yield conservative controller result.

\section{REFERENCES}

[1] Misgeld BJE, Werner J, and Hexamer M. Nonlinear robust blood gas control by state linearisation for the cardiopulmonary bypass. Control Eng Pract 2008; 16:884-95.

[2] Hexamer M., \& Werner (2003). A Mathematical model for the gas transfer in an oxygenator IAFC conference on modelling and control in biomedical systems (pp.409-414).Australia: Melbourne.

[3] Hexamer M, Misgeld B, Prenger-Berninghoff A, et al. Automatic control of the extra- corporal bypass: system analysis, modelling and evaluation of different control modes. BiomedTech 2004; 49:316-21.Kay PH, Munsch CM. Techniques in Extracorporeal Circulation. London: Arnold, 2004.

[4] Robust and self-tuning blood flowcontrol during extracorporealcirculation in the presence of systemparameter uncertaintiesB. J. E. Misgeld J. Werner M. HexamerMedical\& Biological Engineering \& Computing 2005, Vol. 43, PP 589-599

[5] Hammon J Wi . Extracorporeal Circulation: Perfusion SystemCohn Lh, ed. Cardiac Surgery in the Adult. New York: McGraw-Hill, 2008:350-370..

[6] Cardiopulmonary Anatomy \& PhysiologyEssentials for Respiratory Care, 4th EditionTerry Des JardinsCOPYRIGHT (C) 2002 by Delmar, a division of ThomsonLearning

[7] Introduction to Extracorporeal Circulation Maria Helena L. Souza \&Decio O. Elias

[8] A.N.K.Nasir, M.A. Ahmad and M.F.Rahmat, "Performance comparison between LQR and PID Controller for an inverted pendulum system" International Conference on Power Control and Optimization, Chiang May, Thailand, 18-20, July 2008.

[9] Mahmoud, M.S.: 'Switched delay-dependent control policy for water quality systems', IET Control Theory Appl., 2009, 3, (12), pp. 1599-1610.

[10] Zhang, H., Feng, G.: 'Stability analysis and H1 controller design of discrete-time fuzzy large-scale systems based on piecewise Lyapunov functions', IEEE Trans. Syst. Man Cybern., B, 2008, 38, (5),pp. 1390-1401. M. Drummond, "Technological Evolution of Membrane Oxygenators," April, 2005, RevistaBrasileira de Cirurgia Cardiovascular, Vol. 20, pp. 432-467.

[11] Allen J, Fisher AC, Gaylor JD, Razieh AR. Development of a digital adaptive control system for PO2 regulation in a membrane oxygenator. J Biomed Eng 1992; 14:404-11.

[12] Sastry S. Nonlinear Systems. New York: Springer-Verlag, 1999.

[13] Scott I. Mars', Robert H. Bartlett', Janice M. Jenkins3, \& Pierre Ababa. Controller design for extracorporeal life support (1996) 18th Annual International Conference of the IEEE Engineering in Medicine and Biology Society, Amsterdam 1996 .1733-1735.

[14] N. Chauveau, W. Vanneurs, Armurier, \& R. Barthelemy (1992) Closed loop control of blood gases during Surgical extracorporeal circulation IEEE 377-399.

[15] M. Korari and E. Zafriou. Robust Process Control. Prentice-Hall International, Englewood Cliffs, NJ, 1989.

[16] Cooper JB, Newbower RS, Kitz RJ. An analysis of major errors and equipment failures in anesthesia management: consideration for prevention and detection. Anaesthesiology 1984; 60:34-42.

[17] S. Marlow, J. D. S. Gaylor, P. H. Mook, R H. Wildevuur, and IC. M. Taylor, "A pO2Regulation system for membrane oxygenators," ASAIO Truns., vol. 27, pp.299-303, 1981.

[18] De Jong DS, Van Dalen A, Nauta J. Introduction of an automatic oxygen regulation device to be used in combination with bubble oxygenators during cardiopulmonary bypass. Extract from the 19th International Conference of the American Society of Extra Corporeal. Technology 1981. 
International Journal on Soft Computing (IJSC) Vol. 5, No. 3, November 2014

\section{AUTHORS}

M. Dhinakaran obtained his B.E degree in Electrical and Electronics Engineering in the year 2000 from the Madras University and further received M.E. degree in Instrumentation\& Control Engineering in 2003 from the Thapar University, Punjab. Presently he is working as Assistant professor in the Department of Instrumentation Engineering Annamalai University. His areas of research are Bio Medical Instrumentation, Process Control.

S. Abraham Lincon obtained his B.E degree in Electronics\& Instrumentation Engineering in the year 1984 and received M.E. degree in Power System Engineering in 1987 and another M.E degree in Process control and Instrumentation Engineering in 2000. He Completed his Ph.D.in the Field of Process Control in 2008from the Annamalai University, Chidambaram. Presently he is working as a Professor of Instrumentation Engineering in Annamalai University. His areas of research are Process Control, FaultDetection and Diagnosis and Multivariable Control. 